\title{
The Growing Pains of Community Radio in Africa
}

\author{
Emerging Lessons Towards Sustainability
}

\author{
Peter da Costa $^{1}$
}

\begin{abstract}
Community radio is considered as an intervention strategy of choice for deepening participation and community ownership. Donors have funded a proliferation of community radio projects in the Global South, prompted by stories attesting to the power of radio as a tool for social change. The evidence suggests that beyond empowering communities, community radio can catalyse behaviour change and impact positively on wider development outcomes. In practice, the record has been mixed, with sustainability a critical challenge. A recent evaluation found that radio stations created through top-down initiatives tend not to survive when external funding dries up. Where such stations do survive, their purpose often becomes different from what was originally intended. Only in a handful of cases have previously aid-dependent radio stations become sustainable. Informed by insights from practitioners, and evaluation reports and scholarly literature, this article draws some emerging lessons.
\end{abstract}

Keywords: community, radio, media, development, Africa, sustainability

\section{Introduction}

Community radio has grown exponentially in Africa and elsewhere and is harnessed in a myriad of ways by different social actors. Communities see radio as providing them with the space to assert and safeguard local cultures, as a platform through which their rights can be advocated for and claimed, as a means of holding those who govern them to account, and as an agent for social change. Development agencies and international non-governmental organisations (INGOs) see community radio as a conduit for messages aimed at educating on life skills, fostering behaviour change, empowering the grassroots and helping eradicate poverty. As has been well documented, radio stations established in the name of communities have also been used to spread hatred and incite genocide. Conversely, radio is also considered a powerful means of countering extremism, mediating violent conflict and building a culture of peace and tolerance.

However viewed, community radio is as a pivotally important phenomenon because it is accessible, facilitates democratization and makes possible empowerment (Conrad 2011). While the community radio movement is worldwide, its resonance is most felt in places where the world's most vulnerable people eke out precarious livelihoods in a 
bid to escape poverty. It is easy to see why community radio has become such a strategy of choice over the years for those wishing to address poverty at grassroots level: it can reach communities that other forms of broadcasting or media cannot. The reach of individual community radio stations can be considerable, although in practice this varies on a case-by-case basis and is dependent on several factors - including availability of stations in a given area, transmitting power, geographic terrain of the target area, etc. Excluding South Africa, in 2000, a typical sub-Saharan African population of 100,000 people had, on average, 20,000 radio receivers, or one per household. A community of 100,000 people can easily be served by a single local commercial or community radio station, broadcasting on either FM or AM (da Costa 2009). Listeners around the world have attributed significant positive changes in their communities - ranging from decisions to abandon female genital cutting in Sudan to initiatives to set up literacy classes for lower-caste citizens in the Bihar region of India (Greiner 2011).

Different evaluation approaches ${ }^{2}$ have yielded a rich body of anecdotal evidence pointing to the success that community radio has registered in opening up space to air, debate and foster solutions around key issues of concern to the community (cf. Fraser \& Restrepo-Estrada 2002, Jallov 2007). Yet despite its clear potential and widespread proliferation since the 1990s, the impact of community radio has been uneven and its record mixed. This is for a number of reasons. One is that fact that while it has mushroomed in some countries, its presence in others has been thin or absent. In some countries, the expansion of community radio has been hampered by non-existent, inconsistent or hostile legislation. Asian broadcasting legislation, for example, generally lags behind that of Africa and Latin America (Fraser and Restrepo-Estrada 2002). Furthermore, the evidence suggests a high attrition rate, with few community radio stations having arrived at the right formula to remain viable or sustainable.

The purpose of this article is to draw some lessons around sustainability, informed by the experience of selected community radio stations in Africa. The starting point is that sustainability is a multi-faceted and complex construct manifested in diverse ways depending on the local context. Key questions to be addressed will include the following:

- Are community radio stations sustainable beyond donor funding? What happens when donors pull out?

- What are the other determinants of success or failure aside from funding?

- How has success been defined in community radio and have the goalposts shifted over time?

- What factors have helped successful stations achieve sustainability?

In seeking answers to these and related questions, the article will draw on insights from experienced practitioners and review selected evaluation reports and literature relating primarily to community radio in Africa. It should be emphasised at the outset that 'Africa' is hugely complex and diverse, with country and community contexts varying tremendously. Thus, lessons learned from one radio station in a given community may not readily be applicable to other localities. That said this article will attempt to identify common issues and lessons that are likely to resonate beyond the immediate locality. The article's focus is 'community radio' as opposed to 'community broadcasting' or 'community media'. While community broadcasting spans radio, video, television and the 
internet, most attention has been paid to community radio and it is in this 'sub-sector' that experience has yielded the most evidence to date.

The rest of the article will proceed as follows: First, it will define what is meant by 'community radio' and discuss what is known of its footprint and track record in Africa and beyond. Second, it will reflect on the mixed track record of community radio and interrogate why is has fallen short. Third, it will reflect on the key elements that contribute to sustainability as highlighted in the literature. Fourth, it will review two African case studies with a view to extracting key lessons about sustainability. The article will end by drawing some inferences and conclusions about the sustainability of the community radio sector in Africa, and flagging some avenues for further research.

\section{How Is 'Community Radio' Defined and How Has It Evolved?}

Fraser and Restrepo-Estrada (2002) define community radio as being distinct from other forms of broadcasting in that it is a non-profit service owned and managed by a particular community, either through a trust or through a foundation. Additionally, it is managed by the community, and its operations rely mainly on the community's own resources. Its programming is based on audience access and participation and reflects the interests and special needs of the community. The authors identify the following principal functions of community radio: reflecting and promoting local identity, character and culture by focusing principally on local content; creating a diversity of voices and opinions on the air through its openness and participation from all sectors; encouraging open dialogue and democratic process by providing an independent platform for interactive discussion about matters and decisions of importance to the community; promoting social change and development; promoting good governance and civil society by playing a community watchdog role that makes local authorities and politicians more conscious of their public responsibilities; sharing information and innovation; giving voice to the voiceless, especially to women and young people in some societies; and providing a social service as a replacement for the telephone (ibid).

The South African Broadcasting Act 4 of 1999, considered as among the most groundbreaking pieces of broadcasting legislation, provides for community radio as one of three types, along with public and private broadcasting. The Act defines community broadcasting services as: being fully controlled by a non-profit entity and carried on for non-profitable purposes; serving a particular community; encouraging members of the community served or persons associated with or promoting the interests of such community, to participation in the selection and provision of programmes to be broadcast; and funded by donations, grants, sponsorship, advertising or membership fees, or by any combination of these (South Africa 1999, in Banda 2003).

Consistent with the above, the African Charter on Broadcasting has defined community radio as "broadcasting which is for, by and about the community, whose ownership and management is representative of the community, which pursues a social development agenda, and which is non-profit." In this context, the community is taken to be represented by an ownership entity which has civil society or NGO characteristics. Thus, community radio stations tend to be owned by community-based organisations, such as local NGOs, workers organisations, educational institutions, religious or cultural organisations, or by associations of one or more of these forms of civil society entity ${ }^{4}$. 
Local ownership, local content, non-profit and developmental purpose as well as nonpartisan funding have emerged as common dimensions across these as well as other definitions. Each of these has in turn been shaped by the evolution of the community radio movement over the past sixty or so years. In Latin America (and later in South Africa), community radio emerged as part of movements of political struggle opposing repressive governments $^{5}$. Radio Sutatenza, established in 1947 in Colombia, is considered as the first-ever developing world community radio station (Girard 2007). The miners' radios of Bolivia emerged two years later (1949) to press for better working conditions for tin miners, and were supported by the miners themselves, who pledged a portion of their monthly salaries towards the stations' running costs. The backdrop to the emergence of these radio stations was poverty and social injustice, and this was the first recorded use by a sector of society of radio broadcasting to improve its socio-economic status (Fraser \& Restrepo-Estrada 2002).

Because radio sets are cheaply available, portable, run independently of power grids and do not exclude those that are illiterate, radio is far and away the mass-medium of choice for more than two thirds of Africans, both rural and urban. In much of Africa, community radio stations were set up either by governments or with donors as key drivers, to spread development messages and advance poverty reduction. This followed a landmark conference held in Bamako, Mali in 1993 on the theme 'Freedom for African Radios'. Since then the governments of South Africa, Benin and others have recognised the role of community radio and put in place supportive policy, legal and regulatory frameworks ${ }^{6}$. Most recently, in October 2010, the Federal Government of Nigeria announced it was giving the go-ahead for community radio ${ }^{7}$.

A growing number of community radios broadcast without licenses. While more liberal governments, including in Mali and South Africa, are embracing community radio, countries such as Eritrea and Zimbabwe have banned it (Myers 2011). Africa's first community radio station was established at Homa Bay on the shores of Lake Victoria in May 1982, a joint initiative of UNESCO and the Kenyan Government (Githethwa 2010). From the 1990s onwards the sector expanded exponentially, both in Africa and worldwide, growing faster than both state and commercial radio (Myers 2011).

Over the years, UNESCO has actively promoted community radio as an agent for change and development (Fraser \& Restrepo-Estrada 2002) and has been involved in setting up a number of stations, including Radio Dzimwe in Malawi, Radio Katatura in Namibia, and Zambia's Mazabuka community radio stations (Banda 2003). A host of development agencies have followed suit, drawn by the opportunity that community radio affords to advance rights-based approaches hinged around ownership and participation ${ }^{8}$. Community media is increasingly being included in national development plans, due to its potential to facilitate community participation and empowerment as part of poverty eradication or alleviation efforts (Jallov \& Lwanga-Ntale 2007a).

\section{A Mixed Track Record}

The sheer proliferation of radio stations that have come into existence, particularly since the airwaves begun to be liberalised in the 1990s, represents both progress and challenge. In 11 countries surveyed across Africa, local commercial radio grew by an average of 360 percent between 2000 and 2006, whereas community radio grew by a striking 
1,386 percent, on average, over the same period (Myers 2011). Total radio stations range from three or four each in Rwanda and Kenya to countries such as Mali with 159 community radio stations (ibid). Even relatively small countries such as Liberia (with about 34 active community radios) and Sierra Leone (with 24) have seen particularly large increases in recent years. In Mali, community radios grew at a rate of two new stations per month throughout the 1990s (ibid). In Niger alone, citing a 2006 UNDP study, Bathily (2011) identifies a total of 97 community radio stations, established by a consortium of development partners, led by UNDP, ACMAD and SNV, which expanded considerably over time ${ }^{9}$

In South Africa in 2007, 152 of the country's 191 radios were classified as community radio stations, with the rest evenly distributed between public and private. Surveys show that community radio reaches 6.5 million South Africans, with close to a quarter of all radio listeners tuning into a community radio station at least once a week (Girard 2007). Frere (2008) identifies 133 'community, associative, academic and scholarly' radio stations in the DRC, of which 3 are in the capital in Kinshasa. She considers the recent proliferation of such radio stations in the DRC a significant advance, as they offer an alternative to the national media and provide information that is of direct utility to the mainly rural communities they serve.

In as much as these stations represent an alternative means of engaging with and empowering marginalised communities, their very diversity raises a myriad of questions. One is definitional. Frere (2008), for example, cautions that a significant number of DRC community radio stations fall short of the standard definition on a number of counts: they are owned by individuals as opposed to collectively; they generate income from advertising, and their programming is not made with the participation of the communities they serve. Even stations that largely conform to the accepted definition are prone to enter into political debates. Many have succumbed to pressure from local authorities who force them to broadcast messages of support and use them as a vehicle for propaganda. Community radios also find it difficult to attract or retain trained staff, with presenters in DRC often paid no more than a symbolic amount (ibid) ${ }^{10}$. Give or take a few differences, this represents the picture in many African countries.

Another problem is one of reliability. Bathily (2011) reports that despite benefiting from a significant amount of training, organisational development, coaching support visits, and funding of equipment upgrades, many of the community radio stations in Niger remained fragile, with more than $10 \%$ of those studied off the air due to technical problems.

In a five-country study, Girard (2007) finds that many stations have found innovative ways of plugging financing gaps, including selling audio production services. Governments are increasingly recognising the important function community radio stations perform in providing social infrastructure. In some cases, this has provided the stations with revenue from government advertising and public service announcements. In three of the five countries studied (Mali, Colombia and South Africa), specific national programs exist to provide public sector support to community radio, while many stations receive support from local or regional governments. However, despite these positive developments, financial sustainability is assessed to be the principal challenge facing community radio stations, with most of those studied in permanently precarious financial situations (Girard 2007). 
Overall, community radio in Africa is still experiencing growing pains and has not yet come of age. Conrad's (2011) study of six community radio stations in Kenya, Tanzania and Uganda yields some useful findings that can also be generalised. He finds that the environment, in which many community radio stations are not yet a decade old, is: dominated by donors; that very few of the stations are actually operating, with the airwaves dominated by more accessible and popular commercial radio stations; and that discussions around community radio and audience are beset by definitional ambiguity and confusion. Findings include the prevalence of top-down approaches to establishing certain stations; a lack of sufficient community ownership and leadership; funding constraints and distorted incentives.

\section{What Makes for 'Sustainability'?}

All in all, these deficits and challenges add up to a problem of sustainability, with the evidence so far reviewed suggesting that community radio stations are not yet a sustainable feature of the African media and development landscape. As Lush and Urgoiti (2011) point out, until recently sustainability tended to be defined in financial terms. However, as the body of evidence on community radio has grown, the notion of sustainability has come to be seen as a much more complex construct. The most holistic and widely agreed definition is offered by Gumucio Dagron (2001), who identifies three dimensions of sustainability which determine the ability of community radio stations to survive and grow.

The first is 'social sustainability', which refers to community ownership of the station and participation in production and airing of programmes at both decision-making and operational levels. According to this definition, only communities that have 'appropriated' or 'owned' a communication process can make it socially sustainable. The second is 'institutional sustainability', which relates to the ways the broadcasters function: station policies, democratic processes, management styles, internal relationships and practices, and partnerships with external agencies. The third is 'financial sustainability', relating to the station's model for generating revenue and how its funds are managed and accounted for. All three are inter-related and impact upon each other (Gumucio Dagron 2001, in Lush and Urgoiti 2011).

Jallov (2007) offers a slightly different, albeit complementary, definition of sustainability as having the following three components: 'social sustainability' which includes ownership of institutions, processes and ideas, development of local content, language as well as local culture and relevance; 'organisational sustainability' which includes adequate legislation and policies, internal democracy, training and participation, appropriate and democratic structures, management and supervisory bodies, appropriate technologies, and belonging to relevant networks; and 'financial sustainability' which includes the development of realistic budgets, identifying local, national and international funding opportunities and determining the desired funding mix. Jallov's conviction is that "all these elements of building up a radio contribute to, or detract from, sustainability - from the way you organise your community around your radio to the involvement by community producers, and so on" (Jallov 2011). 


\section{Two Case Studies}

To provide added context to some of the issues highlighted above, I now briefly discuss two cases of community radio projects in Africa, drawing on impact assessment reports and project-related evaluation material. Each provides context-specific, if somewhat complementary, insights into the sustainability challenge.

\section{The East African Community Media Project (EACMP) $)^{11}$}

The project was conceived after EcoNews Africa (ENA), an NGO based in Kenya, invited several community-based organisations to a consultation in Nairobi in 1993 around the UN Convention to Combat Desertification. The meeting agreed on radio as the best means of reaching marginalised communities with information relevant to their contexts. Given the limited reach and relevance of government and privately-owned radio stations, and the imperative of mobilising the communities in question to respond to the environmental threats to their livelihoods, the group decided to explore the idea of setting up radio stations owned and managed by the community.

Three pre-existing community radio stations - Uganda Radio Development and Training Programme's Kibaale-Kagadi Community Radio (KKCR) in Kagadi, Uganda; the Orkonerei Radio Services in Terrat, Tanzania; and Radio Mang'elete in Nthongoni, Kenya - agreed to participate in the project. The three were conceived of and hosted by community development organisations ${ }^{12}$, so they emerged on the basis of a developmental rationale and did not exist in a vacuum. ENA took on the role of co-ordinating the project.

The EACMP was thus born, with the Swedish International Development Agency (SIDA) providing support, initially for a first phase (1996-2002) that included technical and social surveys, development of codes of ethics and conduct, social mobilisation and technical and administrative costs. The support also enabled radio production, broadcasting as well as institution building and strengthening ${ }^{13}$. The communities and their organisations have had a strong ownership and increasingly raised funds for recurrent costs and during the establishment built the facilities voluntarily and contributed in kind. SIDA also funded a second phase (2003-2007), during which the partners sought to consolidate the gains made (Jallov 2007).

A key objective of the EACMP was to harness community radio as towards reducing poverty. SIDA defined poverty as being manifested by three lacks - lack of power, lack of choice, and lack of material well-being. Jallov's (2007) impact assessment found that all the three radio stations empowered (through information on rights, governance, dialogue, transparency and debate); endowed the communities with choice (by making them subjects of their own development processes); and facilitated strengthened livelihoods (through income, health, security). Empowerment, participation and change emerged as the most significant change brought about by the community radio stations, followed by tangible improvement in livelihoods. The findings, derived from dialogue with individuals and communities using Most Significant Change methodology, were consonant with Jallov's overall assessment of the sustainability of the stations - namely that while they all scored highly in the domain of social sustainability and ownership, they remain weak in the areas of institutional and financial sustainability ${ }^{14}$. 
A third phase, envisaged between 2007 and 2009, was to have built the capacities of the radio stations for self-sustainability and regional scale-up. However, this phase failed to take off due to the embezzlement of EACMP funds managed by ENA. While the theft was being investigated and pursued through the courts, restructuring at SIDA headquarters triggered a shortage of funds for the Kenya programme, meaning SIDA could not provide the support as anticipated. At the same time, institutional and financial difficulties at ENA meant it did not have the wherewithal to raise alternative funds to support EACMP (Githethwa 2010). This provides an important lesson from the EACMP case: reliance on a single external funder, coupled with sub-standard financial accountability mechanisms, can spell the death-knell of any community radio project, however promising.

Another key lesson learned relates to the importance of having a strong coordinating body to manage funding as well as provide technical backstopping and capacity development support along an 'accompaniment' model. The 2010 collapse of ENA - which had also been instrumental in the establishment of the Kenya Community Media Network (KCOMNET) - left a void that has not yet been filled in the East African sub-region. The community radio community is now considering how to replicate the East African Multimedia Centre (EAMC), set up within ENA in 2009 with support from UNESCO. EAMC's was to operate as a sort of help desk, providing support services to the EAMCP network via a website, call centre and other electronic means ${ }^{15}$.

A third important lesson learned was that the more embedded community radio stations are in strong institutions, and the more networked they are with other stations, the more likely they are to reduce their fragility and improve their sustainability. Radio Mang'elethe, for example, now finds itself in considerable difficulties because it is the only one of the three stations that separated itself from the community-based organisation that originally hosted it. The other two have by and large been able to navigate the difficulties precipitated by the collapse of ENA, fortified by their institutional linkages and dynamic leadership (Githethwa 2010).

\section{Urban Community Radio in Dakar, Senegal}

Dorelli (2010) studied four urban community radio stations in Dakar, Senegal, focusing on their relationship with external funders. The study finds that development agencies now constitute key actors in the Senegalese culture in which community radio operates. Employing discourse analysis, she demonstrates how the radio stations serve their development partners by reporting on their activities and legitimising their work.

Terms such as "good governance", "transparency", "non-state actors" and "regulation between civil society and public policy" are regularly broadcast over the airwaves and gradually become part of the local reality as abstract concepts eventually referring to concrete aspects of the communities' daily lives. To ensure this support, development partners supplement the journalists' income by paying them per diem for attending 'séminaires' (training seminars) to discuss the role of communication in solving development problems.

According to the study, the seminars also serve to transmit the competing donor conceptions of the type of journalism that community radio reporters should practice. The community radio stations therefore have to navigate a careful balancing act between broadcasting the kind of content that resonates with the agendas of their funders, and 
broadcasting content that responds to the needs of the communities they serve.

In a significant departure from the raft of studies that view community radio stations as objects of development, Dorelli's account depicts community radio stations as vital social actors that exemplify and are embedded in the social complexity of contemporary Senegal. The radio stations provide a platform for this complexity to meet, to be mediated, to merge, to be understood, and to participate in the ongoing re-articulation of its society. The stations also serve as space for forces of mediation and interaction between many actors, including government, international sponsors, local NGOs, civil society, and others. Thus, Senegal's community radios are not so much of a tool for development as a "place where society and development meet along the lines of ambivalence and compromise" (ibid, p.7).

The radio stations navigate a sophisticated, albeit precarious, balance between the claim for recognition from the government and the loyalty towards their sponsors. "Community radio is twice a media", he concludes. "[A]s radio it mediates waves to spread a message, and as a social catalytic converter it mediates political and cultural forces. In the end, community radio stations are the radio of 'the community by the community' as they illustrate the compromises and ambivalence of the Senegalese people regarding the government, the international developers, the relation to autonomy and public policies, and to history" (ibid, pp.7-8).

This case sheds interesting light on the field of power in which community radio operates in African countries. On the one hand, they must internalise at least some of the agendas of their funders, such as the discourse of development and Western journalistic methodology and approaches. On the other, they must court state legitimacy, in some cases to secure public funding, but also in order to act as a broker between community expectations and actual state service delivery.

\section{What Have We Learned?}

Drawing on the cases described above, as well as the earlier discussion, what does the evidence tell us about the sustainability of the community radio sector in Africa?

First and foremost, what emerges is a negative correlation between excessive dependence on external funding and sustainability. As the EACMP example demonstrates, reliance on a single funder for the lion's share of its setting up and operating budget further weakens inherently fragile stations. SIDA's withdrawal has threatened the very survival of the stations, all of which are now grappling with the challenge of diversifying funding sources to include funding from the communities they serve. In Niger, community radio stations are almost entirely dependent on funding from development agencies and INGOs, to the extent that they are only able to stay on air with repeated external support.

In his study of six community radio stations in East Africa, Conrad (2011) sought to answer the following research question: "How does external financial ownership of a community radio station in East Africa influence its sustainability and grassroots identity?" He found that each of the stations studied was created and sustained by external donations; that the prevailing ownership model is not sustainable; that relationships between station staff and donors are stronger than the synergy between stations and their audiences; that this model reinforces a "we are poor" mentality - in effect subtracting, as opposed to endowing the community with, agency. 
The EACMP also teaches us that community radio stations are more likely to thrive when they are connected to each other, and are able to share knowledge and resources. A central coordination mechanism that provides technical support and delivers capacity building in key areas of need is also essential and more needs to be invested in such service centres.

A pertinent question, raised by Conrad (2011) is whether community members are agents if they do not own their station, or whether the community merely becomes a setting for externally funded programmes. He seems to imply that community radio stations are objects of external agendas, when he asks: "Donor organisations are clearly building and using stations as resources in carefully targeted communities, but can the community members flip this?" (ibid, 2011 slide 24).

The Senegal case study offers a slightly more nuanced picture that in part responds to Conrad's concern. While their dependence on outside funders means Senegal's urban community radio stations are compelled to internalise external agendas and ways of working, they creatively leverage this external support as a legitimising tool that will ultimately win them state support whilst endowing them with critical autonomy from the powers that be, in the process allowing them to play an important role in animating and providing a voice for their communities.

Ultimately, sustainability transcends the financial to include 'social' and 'institutional' dimensions. While all three are mutually reinforcing, each represent critical pillars around which communities must build and grow their radio stations if these are to endure as mediators of social change.

\section{Conclusion - Building from the Roots Up}

Conrad (2010) offers a useful typology for understanding the roots of community radio ownership: often, a community radio station is built before the community is willing or able to fund it; thus, the tower is planted and then its life-sustaining roots attempt to grow. Because the station was created with external funding, the ownership tends towards the external. With such a model, it becomes an uphill task for the station to build participation, trust, perceived ownership and need. These are four steps through which the station must pass to achieve the fifth, ideal stage, whereby the station operates on the voices and funding of the community; people believe they need the station as much as it needs them; and the station is owned, operated and controlled by/ for the community. According to Conrad's assessment, while all the stations he studied aspire to the fifth stage, none has achieved it.

Bilateral and multilateral development agencies as well as INGOs and even intergovernmental regional organisations within Africa continue to believe in the emancipative power of community media, and of community radio in particular. As an example, in 2010 the African Development Bank (AfDB) announced its intention to conduct a study on community radio in Africa that would inform its emerging focus on so-called 'fragile states" ${ }^{16}$. That a multilateral development bank is seeking to join the proliferation of other actors seeking to build capacity among Africa's community radio stations, this time with a focus on 'fragile states', demonstrates the extent to which the sector is viewed simultaneously as an object and an enabler of development. 
It also cautions communities and their leadership to beware of strangers bearing gifts: in the absence of entrepreneurial and innovative leaders who are able to subvert the agendas of others to community purpose, top-down approaches to building community radio stations will at best lead to the development of a sector whose incentives are distorted and whose purpose will ultimately move away from the accepted definition and understanding of 'community radio'. At worst, the emerging model of community radio stations that routinely fail will continue to be replicated throughout the continent.

To stave off such a pessimistic eventuality, further research is needed into the sector. We know quite a bit about the challenges community radio faces. We need to know much more about what success looks like. We need to know where and in what ways stations have been able to lay the foundations for social, institutional as well as financial sustainability. We need to develop robust tools to assess the impact of these radio stations as social actors, and not simply as conduits for development messages. In short, we need to figure out what it takes to build from the roots up.

\section{Notes}

1. Peter da Costa, $\mathrm{PhD}$, is a communication for development specialist and a consultant to multilateral and bilateral development agencies and philanthropic foundations. E-mail: peter.dacosta@gmail.com

2. These include Outcome Mapping, Most Significant Change and other ethnographic approaches involving communities themselves. Nonetheless, there remains a lack of a precise methodology for assessing the social impact of community radio and much of the available evidence is anecdotal (Jallov 2007).

3. Additionally, the Act states that programming provided by community broadcasting services must reflect the needs of the people in the community. Among other cultural, religious, language and demographic needs it must: provide a distinct broadcasting service dealing specifically with community issues not normally dealt with by other broadcasting services covering the area; be informational, educational and entertaining; focus on the provision of programmes that highlights grassroots community issues including developmental issues, health care, basic information and general education, environmental affairs, local and international issues and the reflection of local culture; and promote the development of a sense of common purpose with democracy and improve quality of life (ibid).

4. It should of course be noted that these may not be representative of the community as a whole. For example, they may come from a particular ethnic or religious group (da Costa 2009).

5. According to Myers (2011), community radio has particularly thrived in Latin America, where it has a long history, is numerically significant, and where it has arguably fulfilled more of a public service function than state broadcasters, which have been notorious for their lack of independence. She identifies Colombia, Bolivia, Mexico, and Argentina as having particularly favourable pro-community broadcasting policies. Some estimates put the total number of community radio stations in Latin America at around 10,000, with Peru having the largest proportion and Ecuador, Bolivia, and Brazil in second, third, and fourth place. If unlicensed stations are also taken into account, the overall numbers are much higher, with recent surveys by UNESCO, for example, showing there are more than 10,000 community radio stations still waiting for licenses in Brazil alone (Ibid).

6. In addition to legal recognition, these supportive frameworks include clear definition of a social purpose for community radio; reserved radio spectrum at adequate power; fair and transparent licensing procedures; affordable or free broadcast licences; and access to multiple funding facilities or a state-established community radio fund (da Costa 2009).

7. See http://na.amarc.org/?p=shownews\&id=1155

8. Ideas of participatory development began to influence development cooperation in the $1970 \mathrm{~s}$, promoted by Chambers and the IDS school. Community radio soon emerged as the tool of choice for development agencies looking to reach and engage marginalised communities in rural areas with poor infrastructure (Dorelli 2010).

9. Subsequent members include Africare, UNFPA, Helen Keller International, Karkara, Agence intergouvernmentale pour la francophonie (AIF), PDCII, Moriben, Care International, Icrisat, VSF, UNESCO, Project Keita, Cooperation Suisse, Catholic Relief Services, B/M and FAO, among others (Bathily 2008).

10. Estimated at between $\$ 10$ and $\$ 50$ a month. 
11. A full examination of the milestones, challenges and impacts of the EAMCP is beyond the scope of this short paper. However, a detailed discussion of the project can be found in Githethwa's 2011 paper (referenced in the bibliography), which also provides a fascinating review and analysis of the evolution of the various associations and coordinating bodies around community radio in Kenya during the lifecycle of the EACMP.

12. The Mang'elete Community Integrated Development Project (MCIDP) in Nthongoni, Kenya; the Institute for Orkonerei Pastoralist's Advancement (IOPA) in Terrat, Tanzania; and the Uganda Rural Development and Training Program (URDT) in Kagadi, Uganda.

13. SIDA was the biggest donor to each of the three stations. ORS in Tanzania, for example, received US\$ 45,000 a year for the first three years, and $\$ 25,000$ in the fourth year, on the understanding that SIDA support would no longer be needed after 2006. SIDA also provided an additional co-ordination grant to ENA (Developing Radio Partners 2005).

14. A list of 111 stories of change can be found on pages 16-21 of the Jallov 2007 paper, which provides a synthesis of the three impact assessment case studies.

15. A similar concept to the EAMC is the National Community Radio Help Desk, set up by the Bangladesh NGOs Network for Radio and Communication (BNNRC) to offer various services including: enquiries on community radio; budget and planning; assistance in filling forms and following up with the concerned Departments, Ministries and Commissions; assistance in acquiring relevant software; baseline studies and need analysis; monitoring and evaluation; capacity building including training on radio content production, editing and presentation; transmission management; library and Archives; feedback; and identification of partners and funding agencies (Githethwa 2010).

16. According to the terms of reference, the AfDB is seeking a consultant to: Map community radios in "Fragile States" (as defined by AfDB), taking into consideration its origins, its community ownership structures, its participatory production processes, its purpose; Identify strengths and weaknesses of each community radio studied; Define the community radios' main audience and languages; list main themes developed in radio programmes; assess community radios' technical capacity; list the community radios' main partners; provide an in-depth analysis of the social, institutional and financial sustainability of community radios in the areas to be studied; provide recommendations for capacity building and technical improvement of community radios in the areas to be studied; and establish connection with AMARC Africa (AfDB 2010).

\section{References}

African Development Bank (2010) Terms of Reference for the Recruitment of International Consultant to Conduct Study on Community Radios in Sub-Saharan Africa with focus on "Fragile States".

Banda, F. (2003) Community Radio Broadcasting in Zambia: A Policy Perspective. PhD Thesis, University of South Africa.

Bathily, A. (2011) Personal communication August 2011.

Conrad, D. (2011) Lost in the Shadows of the Radio Tower: A Return to the Roots of Community Radio Ownership in Kenya, Uganda and Tanzania. What happens when / if the donor leaves? Presentation delivered at the 2011 International Communication Association Conference. 28 May 28 2011, Boston.

Dorelli, J. (2010) 'Media of Autonomy: Community Radios of Dakar'. Downloaded from http://startrek.ccs. yorku.ca/ topia/docs/intersections2010/Dorelli.pdf on 15 August 2011.

Fairbairn, .J and Siemering, B. (2007) Guidebook on Sustainability. Developing Radio Partners.

Fraser, C. and Estrada, S.R. (2001) The Community Radio Handbook. Paris. UNESCO.

Fraser, C. and Estrada, S.R. (2002) Community Radio for Change and Development. In Development 45 (4), p.69-73. Society for International Development (Sage Publications).

Frère, Marie-Soleil (2008) Le paysage médiatique congolais: état des lieux, enjeux et défis. Une étude réalisée sous la supervision de France Coopération Internationale, avec l'appui de la coopération britannique et de la coopération française. Octobre 2008.

Girard, B. (2007) Empowering Radio - Good practices in development and operation of community radio: issues important to its effectiveness. Report prepared for the Programme on Civil Engagement, Empowerment and Respect for Diversity, World Bank Institute (WBI). June 2007.

Githethwa, N. (2010) Milestones, Challenges and Proposals in the Development of Community Radio in Kenya. A Discussion Paper presented at the AUF - ACDM meeting on $21^{\text {st }}$ February, 2010 as a framework of discussions and a guide to further action.

Greiner, K. (2010) Applying Local Solutions to Local Programs: Radio Listeners as Agents of Change. Prepared for the USAD Peace through Development Project by Equal Access, under subcontract to the Academy for Education and Development. 29 October 2010. 
Girard, B. (2007) Empowering Radio. Good practices in development \& operation of community radio: Issues important to its effectiveness. World Bank Institute, Program on Civic Engagement, Empowerement \& Respect for Diversity, 2007.

Jallov, B. (2011) Personal communication August 2011.

Jallov, B. (2011) Empowerment Radio - Voices Building the Community (Forthcoming).

Jallov, B. (2007) Community Radio in East africa: An Impact and Sustsinability Assessment of Three Community Radios within the EACMP. Commissioned by SIDA Department for Democracy and Social Development. Birgitte Jallow Communication Partners. January 2007.

Jallov, B. and C. Lwanga-Ntale (2007) Impact Assessment of the East African Community Media Project 2000-2006: Report from Radio Mang'elete Radio in Kenya, and selected communities. Commissioned by SIDA Department for Democracy and Social Development. Birgitte Jallow Communication Partners. January 2007.

Jallov, B. and C. Lwanga-Ntale (2007) Impact Assessment of the East African Community Media Project 2000-2006: Report from Orkonerei Radio Service (ORS) in Tanzania and selected communities. Commissioned by SIDA Department for Democracy and Social Development. Birgitte Jallow Communication Partners. January 2007.

Jallov, B. and C. Lwanga-Ntale (2007) Impact Assessment of the East African Community Media Project 2000-2006: Report from Kibaale-Kagadi Community Radio, Uganda, and selected communities. Commissioned by SIDA Department for Democracy and Social Development. Birgitte Jallow Communication Partners. January 2007.

Lush, D. and Urgoiti, D. (2011) The Sustainability of Community Broadcasting in Namibia: An Assessment and Plan of Action. A study commissioned by the Friedrich Ebert Foundation's Africa media programme (FES Media).

Myers, M. (2011) Voices from Villages. Community Radio in the Developing World. A report to the Center for International Media Assistance. 5 April 2011.

Myers, M. (2008) Radio and Development - A Concept Paper. Prepared for the International Development Research Centre (IDRC) August 2008 (Updated March 2009). 